\title{
GIS INTEGRATION OF ASTER STEREO IMAGERY FOR THE SUPPORT OF WATERSHED MANAGEMENT
}

\section{N. CHRYSOULAKIS* \\ M. DIAMANDAKIS \\ P. PRASTACOS}

Selected from papers presented at the $8^{\text {th }}$ International Conference on Environmental Science and Technology,

8 - 10 September 2003, Lemnos, Greece.
Foundation for Research and Technology - Hellas, Institute of Applied and Computational Mathematics, Regional Analysis Division P.0. Box 1527, GR-71110, Heraklion, Crete, Greece

*to whom all correspondence should be addressed: tel: +30 2810391762 , fax: +302810 391761 e-mail: zedd2@iacm.forth.gr

\begin{abstract}
In this study, ASTER (Advanced Spaceborne Thermal Emission and Reflection Radiometer) stereo imagery was analysed in combination with Global Positioning System (GPS) data and field observations, using Geographical Information Systems (GIS) techniques to examine the potential of satellite remote sensing to support watershed management. Terrain elevation data were derived for the region of Heraklion, Crete. The accuracy of the ASTER derived DEM (Digital Elevation Model), was better than 20 meters (planimetric) and better than 15 meters (elevation). Supervised classification techniques were applied for land cover production using ASTER multi-spectral imagery and filed observations at predefined application sites. The determination of training areas required in the supervised classification scheme was based on these observations. Finally, GIS methods were applied to estimate watershed characterization parameters for the study area offering the advantages of spatial data handling capabilities and automatic extraction of thematic information. The drainage pattern, which was derived, provided a generally representative depiction of the watershed. The output pixel spacing of 15 $\mathrm{m}$ of the produced DEM as well as the high spatial resolution of ASTER imagery found to be quite satisfactory for the watershed characterization of the study area, indicating the high potential of ASTER imagery to support watershed management.
\end{abstract}

KEYWORDS: Digital Elevation Model, Stereoscopic Analysis, Global Positioning System, Multi-spectral Classification, Watershed Management.

\section{INTRODUCTION}

Watershed management addresses the various elements related to reservoir identification given the watershed characteristics in an integrated manner that consider socio-economic issues, as well as, environmental aspects related to flood and drought risks. The watershed is subject to hydrologic processes that are affected by spatial variability of many parameters such as soils, topography, land cover/use, climate and humaninduced changes and management. Therefore the integration of spatial data handling capabilities of 
a Geographic Information System (GIS) with hydrologic or hydraulic models offers the advantage of having information content of the spatially distributed data to analyse the involved process. Watershed characterization requires at the first step, the construction of a Digital Elevation Model (DEM) to be completed by thematic maps for land use and cover, in addition to other terrain information. DEMs of usable details are still not available for much of the Earth, and when they are available they frequently lack sufficient accuracy. For the production of DEMs from optical satellite data, the respective satellite sensors should have stereo coverage capabilities. To obtain stereoscopy with images from satellite scanners, two solutions are possible (Toutin, 2001; 2004): a) the along-track stereoscopy with images from the same orbit using fore and aft images; and b) the across-track stereoscopy from two different orbits. The second solution was the most used since 1980: first, with Landsat from two adjacent orbits, then with SPOT using acrosstrack steering capabilities, and finally with IRS1C/D. In the last few years, the first solution was used with the JERS-1 OPS, the German Modular Opto-Electronic Multi-Spectral Stereo Scanner (MOMS) and the Advanced Spaceborne Thermal Emission and Reflection Radiometer (ASTER). The viability of stereo correlation for parallax difference/height measurement from digital stereoscopic data has been described and evaluated in previous studies (Lang and Welch, 1999; Ackermann, 1994; Bolstad and Stowe, 1994). AIRousan and Petrie (1998) evaluated commercial software, for the extraction of DEMs using SPOT data. Cheng, et al. (1999) generated a DEM from raw IRS-1C LISS stereo-images, over a mountainous area in Arizona. Toutin and Cheng (2001) presented results for extraction of DEM from very high spatial resolution IKONOS images, and high spatial resolution ASTER and Landsat $\mathrm{ETM}+$ images.

Recently, at the local level, a number of data sources have been used to derive land cover products, including Landsat TM data for high-resolution studies (Steininger, 2000). These studies have been carried out for a number of different applications, including estimation of biomass (Steininger, 2000) and vegetation mapping (Muchoney et al., 2000). Vani and Sanjeevi (2002) evaluated the potential of ASTER VNIR (Visible and Near Infrared) and SWIR (Short Wave Infrared) sensors for land cover mapping. Information in the VNIR image contributed to the enhancement of vegetation and water classes. Rock and soil units were enhanced due to the contribution by the information in the SWIR images. One of the main problems when generating land cover maps from digital images is the confusion of spectral responses from different features. Sometimes two or more different features with similar spectral behaviour are grouped into the same class, which leads to errors in the final map. The accuracy of the map depends on the spatial and spectral resolution and the seasonal variability in vegetation cover types and soil moisture conditions (Congalton, 1988). Attempts have been made to improve the accuracy of image classification. One approach is the use of multitemporal imagery to distinguish classes (Conese and Maselli, 1991; Barbosa et al., 1996). Another is the piecewise linear classifier with simple postprocessing (Huang and Mausel, 1993). The integration of GIS with ancillary information has also been tested, to improve image classification. Gastellu-Etchegorry et al. (1993) and Ortiz et al. (1997) integrated GIS with information about soils, topography and bio-climate. Similarly, Palacio-Prieto and Luna-Gonzalez (1996) employed GIS rules with ancillary data on terrain mapping units and elevation data.

DEM and land cover products are primary inputs for hydrologic models for surface runoff that affects infiltration, erosion, and evapotranspiration, playing important role in determining the runoff characteristics of a specific catchment area. A hydrologic land cover classification must incorporate the ability to display information not only about vegetative species, but also about the land surface and what classes are important hydrologically. To be useful this classification must incorporate elevation, slope, aspect, surface roughness, and vegetation species derived from satellite imagery and classification of that imagery. Satellite remote sensing and GIS have been found useful tools in identification and categorisation of watersheds on the basis of natural resources and their limitations. Drainage basins, catchments and sub-catchments are the fundamental units for the management of land and water resources. Catchments and watersheds have been identified as planning units for administrative purpose to 
conserve these precious resources (Khan, 1999). The concept of watershed management recognises the inter-relationships between land cover/use, soil and water and the linkage between uplands and downstream areas.

In this study, high spatial resolution satellite imagery was analyzed in combination with Global Positioning System (GPS) data and field observations, using GIS techniques, to provide DEM, land cover thematic maps and watershed characterization products, capable of supporting watershed management.

\section{DATA AND METHODOLOGY}

The data used in this study were an ASTER image of August 10, 2000, over the region of Heraklion, Crete, Greece and GCPs (Ground Control Points) derived from GPS measurements. The ASTER method is used because it gives a strong advantage in terms of radiometric variations versus the multi-date stereo-data acquisition with across-track stereo, which can then compensate for the weaker stereo geometry. Field observations have been also used for training site selection for the supervised classification of ASTER multi-spectral imagery.

ASTER is an advanced multi-spectral imager that was launched on board NASA's Terra spacecraft in December, 1999. ASTER covers a wide spectral region with 14 bands from the visible to the thermal infrared with high spatial, spectral and radiometric resolution. ASTER consists of three separate instruments subsystems, each operating in a different spectral region, using separate optical system. These subsystems are the VNIR, the SWIR and the thermal infrared (TIR). The spatial resolution varies with wavelength: $15 \mathrm{~m}$ in the VNIR, $30 \mathrm{~m}$ in the SWIR and $90 \mathrm{~m}$ in the TIR. The VNIR subsystem consists of two telescopes one nadir looking with a there band detector (Channels 1, 2 and 3N) and the other backward looking $\left(27.7^{\circ}\right.$ off-nadir) with a single band detector (Channel 3B). The SWIR subsystem consists of one telescope with a six band detector (Channels 4, 5, 6, 7, 8 and 9). The TIR subsystem consists of one telescope with a five band detector (Channels 10, 11, 12, 13, and 14). The most important specifications of the ASTER stereo subsystem that govern the DEM generation capabilities, include: stereo geometry; platform altitude of 705 $\mathrm{km}$ and ground speed of $6.7 \mathrm{~km} \mathrm{~s}^{-1}$; base to height ratio $(\mathrm{B} / \mathrm{H})$ of 0.6 ; IFOV of $15 \mathrm{~m}$; band-pass of 0.76-0.86 micrometers in channel $3 \mathrm{~N}$ and $3 \mathrm{~B}$, both with an MTF of $0.24 ; 9$ seconds required to acquire a $60 \times 60 \mathrm{~km}$ scene; 64 seconds required to acquire a stereo pair (Lang and Welch, 1999).

ASTER 3N and 3B images were used for DEM production, whereas VNIR and SWIR imagery were used for land cover classification and mapping. Field GPS measurements were also performed to provide GCPs for DEM correction and geo-location, as well as to support field observations and training site selection for the necessary for land cover mapping supervised classification. Finally, GIS tools were used for the watershed characterization. The overall methodology is shown in Figure 1.

A digital stereo correlation approach used to calculate parallax differences from ASTER stereo pair. The mathematical concept of one approach to stereo correlation is given by Lang and Welch (1999). Relative ground elevations were determined by measuring the parallax differences in the registered images. The parallax differences were converted to absolute elevations with the use of GCPs. The image coordinates of the GCPs in conjunction with their map coordinates allowed the development of transformation equations needed to register the stereo images and eventually geodetically rectify them to the Earth's surface. The used geometric model was a rigorous parametric model developed at the Canada Centre for Remote Sensing (Toutin, 1995). Assuming parallax difference correlation errors in the range of 0.5 to 1.0 pixels (7-15 m), elevation errors (RMSEz) would be in the $\pm 12 \mathrm{~m}$ to $\pm 26 \mathrm{~m}$ range. The Root Mean Square Error (RMSE) in $\mathrm{XY}$ (planimetry) and Z (elevation) were used for the DEM accuracy assessment.

Following, the land cover classification scheme was established for ASTER VNIR and SWIR imagery. The differential GPS used for the positioning of training areas and for the collection of ground truth data during the field observations. A supervised classification technique was performed employing the Bayesian Maximum Likelihood Classifier. The maximum likelihood method was adopted using the training samples obtained from the ground truth. Assessing the hydrologic response of the watershed using spatially distributed characteristics could provide a valuable tool for hydrologic research and water- 


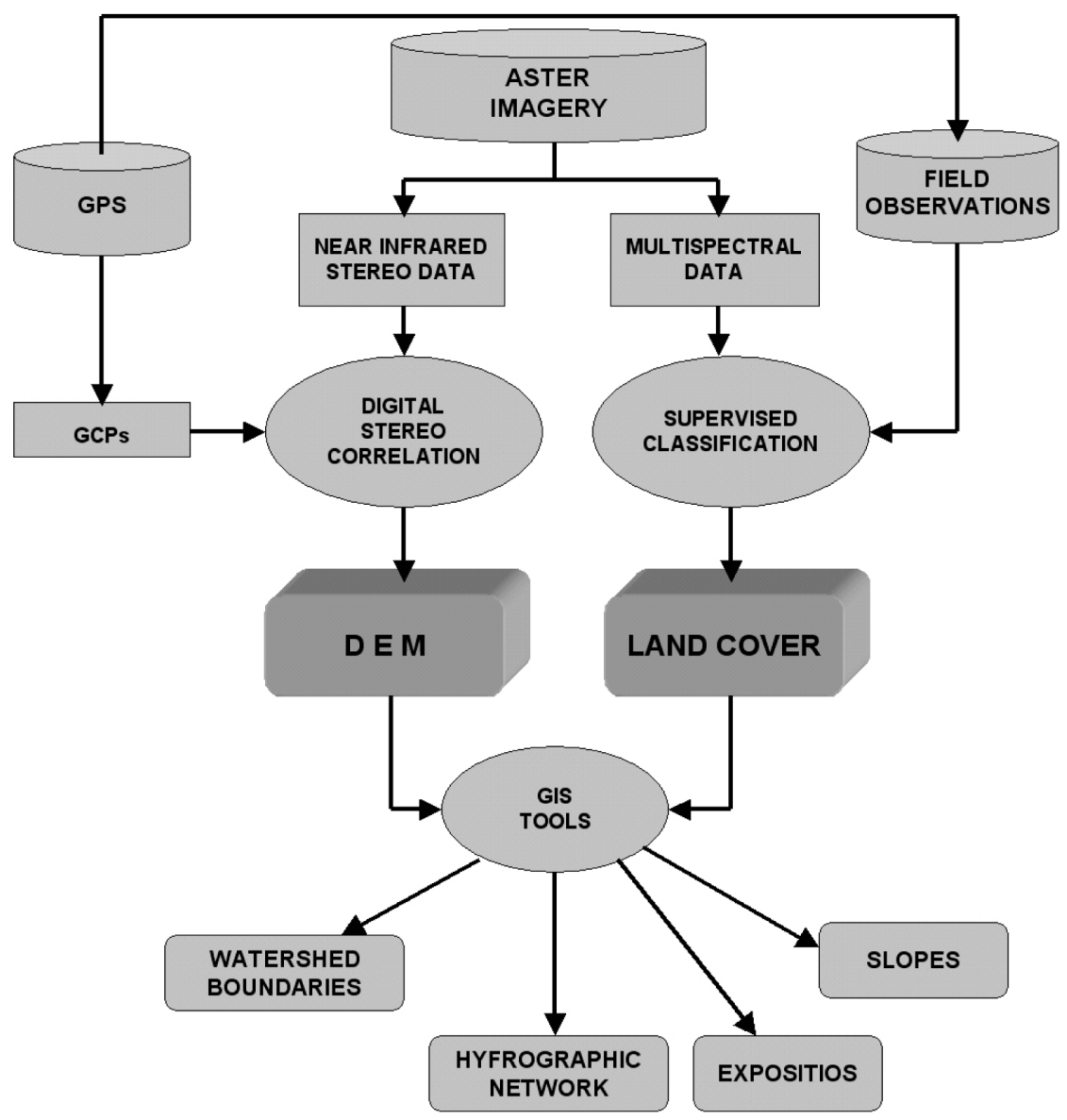

Figure 1. The methodology steps.

shed management. In this study, the DEM and land cover products were used for a GIS-based watershed characterization in the NW Heraklion prefecture area to determine: a) the hydrographic network and oulets; b) the maps of slopes, and aspects and c) the boundaries and geometric characteristics of the watershed and sub-basins. Essentially four steps were carried out to delineate the drainage network: removing sinks in the DEM, assigning flow direction per cell, assigning flow accumulation values per cell, and determining the threshold flow accumulation value that best represented the drainage pattern (Jenson and Domingue, 1998). Additional analysis steps were carried out to derive physical characteristics of the watershed from the elevation data. Elevation and flow direction were the essential data from which all of the other drainage computations were made. The slope was determined from the change in elevation divided by the distance between cells, determined between the cen- tres of the cells in question. The ESRI ArcView flow accumulation function was used to query the flow direction grid to identify those cells deemed to be upslope of the cell in question and create a grid of accumulated flow to each cell by summing the weight for all cells that flow into each downslope cell. Once the flow direction and flow accumulation were determined, stream networks were identified by setting a threshold for the flow accumulation to define the beginning of a stream. Watersheds for any point were determined by identifying all cells that flow into a particular cell of interest. With the aid of the flow accumulation, the location of the watershed outlet was determined and an outlet feature point was created. A minimum threshold was defined and all of the DEM points upstream from the defined outlet were connected together to form a stream network of feature lines. Using the outlets on the stream network and the flow directions, the contributing DEM points for each outlet were 
assigned the proper basin ID. The boundaries between DEM points with different basin IDs were converted to feature polygons. Once the boundaries of the sub-basins were determined, geometric properties important for hydrologic modelling (area, slopes, runoff distances, etc.) may be computed from the DEM data.

\section{RESULTS}

ASTER VNIR stereo imagery was used for DEM production with the support of stereo GCPs. PCI photogrammetric software (Orthoengine) was employed for DEM production. Figure 2 shows the produced DEM for the NW Heraklion area. Catchments and mountainous areas are clearly

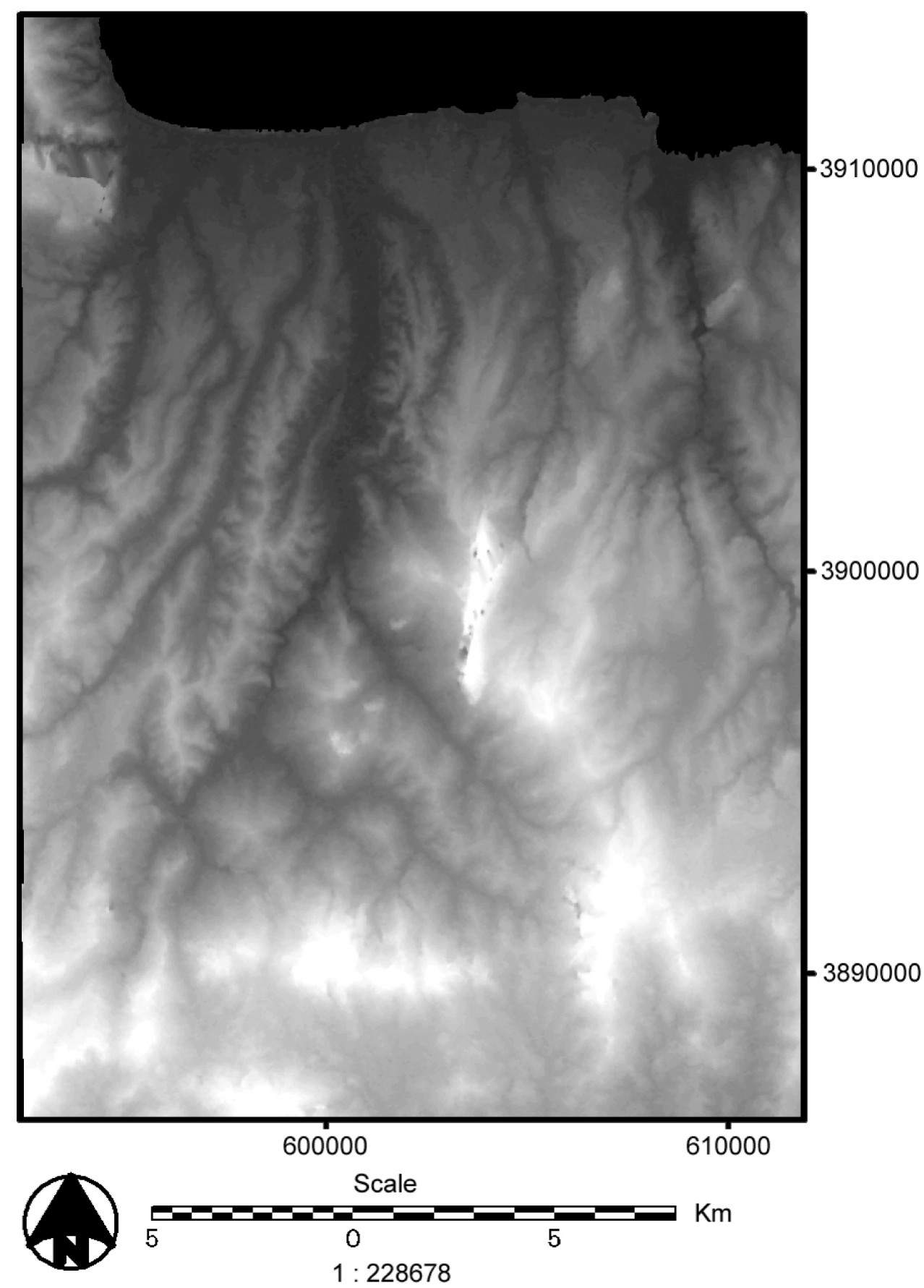

Figure 2. DEM for the NW Heraklion area as derived from ASTER stereo imagery. 
depicted. DEM planimetric accuracy was estimated at $\pm 15 \mathrm{~m}$, whereas its vertical accuracy was estimated using survey monuments, available from 1:5000 topographic maps for the Prefecture of Heraklion. It was founded that (with $95 \%$ confidence) the RMSE was $\pm 11 \mathrm{~m}$. GIS techniques were used for slope and aspect extraction from the produced DEM.

Following, the developed land cover classification scheme was applied in ASTER VNIR and SWIR imagery. Eight classes were defined: a) water, b) urban areas, c) bare soil, d) sclerophyllous vegetation, e) natural grasslands, f) olive trees, g) vineyards and h) complex cultivated patterns. Several training areas for each class were defined and located using the GPS system and evaluated to make sure there was suitable discrimination of individual classes. Then a supervised classification was performed using the training samples obtained from the ground truth. Because a hydrologic land cover classification must incorporate the ability to display information about what classes are important hydrologically, an additional classification step was adopted. The aforementioned five vegetation classes provided by the supervised classification process, as well as the elevation and the slope for each pixel provided by the DEM were used in this step. Furthermore, using the criterion of steep and gentle slopes for the vegetative areas, 13 classes were finally produced. The final classification product is presented in Figure 3. This land cover product can be used as a GIS coverage providing land cover classes that are hydrologic in nature, and which are conducive to hydrologic modelling.

DEM and land cover products were used as input in GIS tools for the watershed characterization process as shown in Figure 1. Elevation and flow direction were the essential data from which all of the other drainage computations were made. Using the flow accumulation function, the location of the watershed outlet was determined and an outlet feature point was created. The watershed was subdivided into subbasins by converting the nodes along the stream feature arcs to outlet nodes. Figures 4 and 5 show the hydrographic network and the watershed boundaries, respectively, two of the final watershed characterization products derived from GIS analysis.

\section{CONCLUSIONS}

In this study, high spatial resolution ASTER imagery was analysed in combination with GPS data and field observations to provide DEM, land cover thematic maps and watershed characterization products, capable of supporting watershed management. The ASTER method was used because it gives a strong advantage in terms of radiometric variations versus the multi-date stereo-data acquisition with across-track stereo, which can then compensate for the weaker stereo geometry. Near infrared stereo imagery was used for DEM production, whereas VNIR and SWIR imagery were used for land cover classification and mapping. Field measurements performed to provide GCPs for DEM correction and geo-location, as well as to support field observations and training site selection for the necessary for land cover mapping supervised classification. Likewise, a hydrologic land cover classification scheme was applied by combining the vegetation classes provided by the supervised classification process with the slope for each pixel provided by the DEM. Finally, GIS tools were used for the watershed characterization. GIS methods were applied to estimate watershed characterization parameters offering the advantages of spatial data handling capabilities and automatic extraction of thematic information. The sinks in the DEM were removed, the flow direction and the flow accumulation values per cell was assigned and drainage pattern was extracted providing a generally representative depiction of the watershed. The planimetric and elevation accuracy of the produced DEM $( \pm 15$ and $\pm 11 \mathrm{~m}$, respectively) are considered quite satisfactory for large catchment hydrological parameterisation, indicating the high potential of ASTER multi-spectral imagery to support watershed management. 

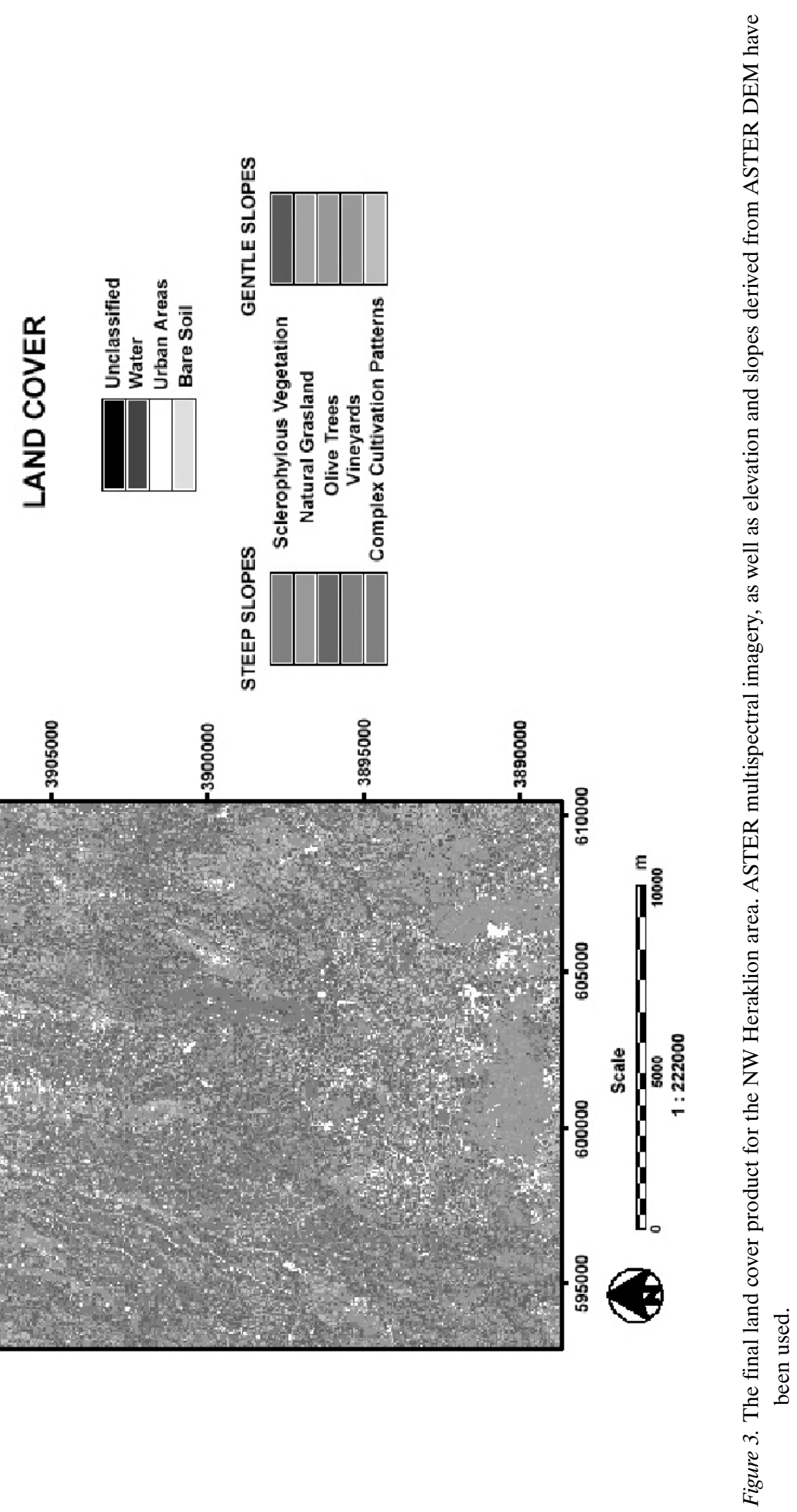


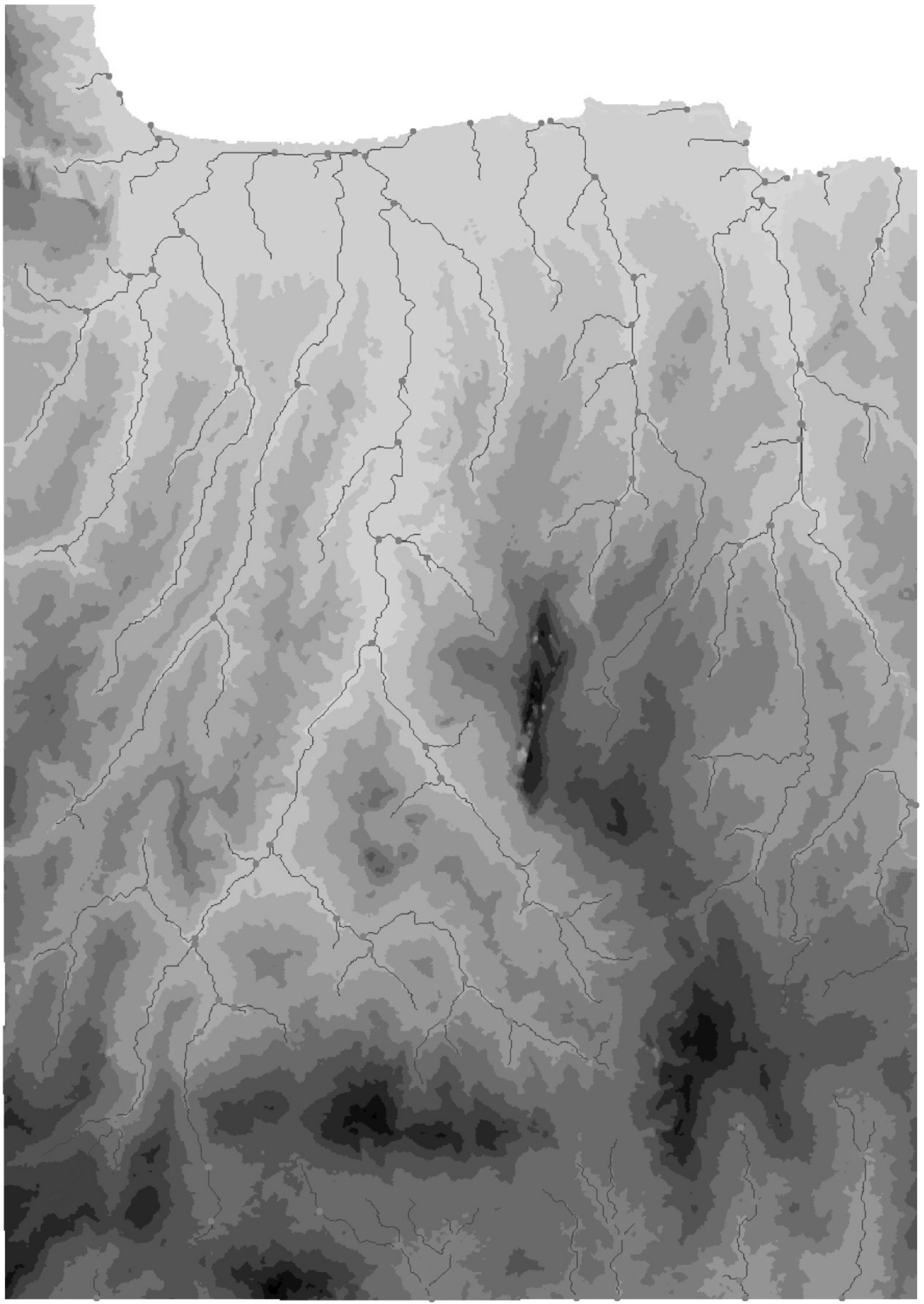

Figure 4. Watershed outlets and hydrographic network. 


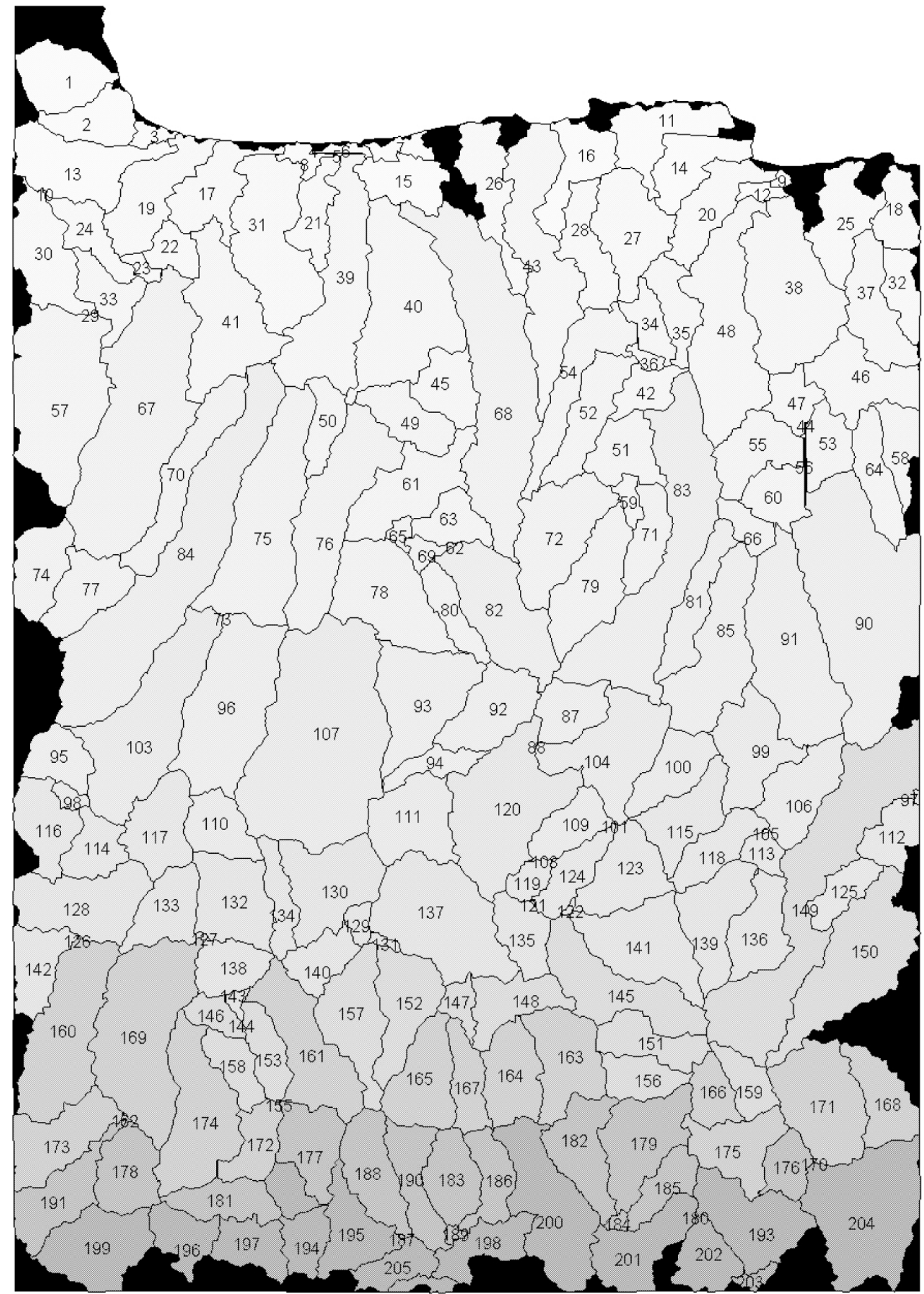

Figure 5. Sub-basins identification and watershed boundaries. 


\section{REFERENCES}

Ackermann, F. (1994), Digital Elevation Models - techniques and application, quality standards, development, International Archives of Photogrammetry and Remote Sensing, 30, 421- 432.

AI-Rousan, N., and Petrie, G. (1998), System calibration, geometric accuracy testing and validation of DEM and orthoimage data extracted from SPOT stereopairs using commercially available image processing systems, International Archives of Photogrammetry and Remote Sensing, 32, 8 - 15.

Barbosa, P. M., Casterad, M. A. and Herrero, J. (1996), Performance of several Landsat 5 Thematic Mapper (TM) image classification methods for crop extent estimates in an irrigation district, International Journal of Remote Sensing, 17, 3665 - 3674.

Bolstad, P.V. and Stowe, T. (1994), An evaluation of DEM accuracy: Elevation, slope and aspect, Photogrammetric Engineering and Remote Sensing, 60, 1327 - 1332.

Cheng, P., Toutin, Th. and Stohr, C. (1999), Automated DEM Extraction from Aerial Photos or Optical Satellite Images, In: Proceedings of the $13^{\text {th }}$ International Conference on Applied Geologic Remote Sensing, March 1-3, 1999, Vancouver, Vol. 1, pp. 56-63.

Conese, C. and Maselli, F. (1991), Use of multi-temporal information to improve classification performance of TM scenes in complex terrain, ISPRS Journal of Photogrammetry and Remote Sensing, 46, 187 - 197.

Congalton, R.G. (1988), Using spatial autocorrelation analysis to explore the errors in maps generated from remotely sensed data, Photogrammetric Engineering and Remote Sensing, 54, 587-592.

Gastellu-Etchegorry, J.P., Estreguil, C. and Mougin, E. (1993), A GIS based methodology for small-scale monitoring of tropical forests - A case study in Sumatra, International Journal of Remote Sensing, 14, 2349 - 2368.

Huang, K. Y. and Mausel, P. (1993), Spatial post-processing of spectrally classified video images by a piece wise liner classifier, International Journal of Remote Sensing, 14, 2563 - 2573.

Jenson, S. K. and Domingue, J. O. (1998), Extracting topographic structure from digital elevation data for geographical information system analysis, Photogrammetric Engineering and Remote Sensing, 54, 1593 1600.

Khan, M. A. (1999), Water balance and hydrochemistry of precipitation components in forested ecosystem in the arid zone of Rajasthan, India, Hydrological Science Journal, 44, 149 - 161.

Lang, H. and Welch, R. (1999), ATBD-AST-08 Algorithm Theoretical Basis Document for ASTER Digital Elevation Models, Rep. Standard Product AST14, The Jet Propulsion Laboratory, California Institute of Technology, Los Angeles.

Muchoney, D., Borak, J., Chi, H., Friedl, M., Gopal, S., Hodges, J., Morrow, N. and Strahler, A. (2000), Application of the MODIS global supervised classification model for vegetation and land cover mapping of Central America, International Journal of Remote Sensing, 21, 1115 - 1138.

Ortiz, M. J., Formaggio, R. and Epiphanio, J. C .N. (1997), Classification of croplands through integration of remote sensing, GIS and historical database, International Journal of Remote Sensing, 18, 95 - 105.

Palacio-Prieto, J.L. and Luna-Gonzalez, L. (1996), Improving spectral results in a GIS context', International Journal of Remote Sensing, 17, 2201 - 2209.

Steininger, M. K. (2000), Satellite estimation of tropical secondary forest above-ground biomass: data from Brazil and Bolivia, International Journal of Remote Sensing, 21, 1139 - 1175.

Toutin, Th. (2004), Geometric processing of remote sensing images: models, algorithms and method, International Journal of Remote Sensing, 25, 1893 - 1924.

Toutin, Th. (2001), Elevation Modelling from Satellite VIR Data: A Review, International Journal of Remote Sensing, 22, 1097 - 1125.

Toutin Th. (1995), Multi-source Data Fusion with an integrated and Unified Geometric Modelling, Advances in Remote Sensing EARSeL Journal, 4, 118 - 129.

Toutin, Th. and Cheng, P., (2001), DEM Generation with ASTER Stereo Data, Earth Observation Magazine, 10, June 2001.

Vani, K. and Sanjeevi, S. (2002), Fusion of ASTER image data for enhanced mapping of landcover features, The Geographic Information Systems Portal (URL: http://www.gisdevelopment.net). 